\title{
Does maintain consistency with a high quality of cardiac compression force between diastole and systole phase?
}

\author{
Seung-Hyun Hyun, Che-Cheong Ryew* \\ Department of Kinesiology, College of Natural Science, Jeju National University, Jeju, Korea
}

The aim of the study was to analyze the cardiac compression force using the vertical force with normalized $(100 \%)$ in cardiopulmonary resuscitation. Nineteen subjects with basic life support license and instructor career participated in this study. Cardiac compression was performed in a situation positioned practical manikin on ground reaction force and with $1,000 \mathrm{~Hz}$ of sample rate. Cardiac compression force in vertical direction showed significant difference among 30 times cardiac compression. Vertical cardiac compression force (N) showed significant difference according to the 30 times of cardiac compression in each di- astole (45.79 N) and systole (714.38 N) phase. Also, normalized vertica force showed significant difference according to the 30 times cardiac compression in each diastole $(6.80 \%)$ and systole $(93.20 \%)$ phase. This suggests that there is a greater difficulty in performing diastole forces close to $0 \%$ than performing a sufficient maximal cardiac compression force in cardiopulmonary resuscitation.

Keywords: Cardiac compression force, Diastole, Systole, Normalize $100 \%$, Ground reaction force, Exercise rehabilitation

\section{INTRODUCTION}

Cardiac compressions generate a small but critical amount of blood flow to the heart and brain (Rajab et al., 2011). Providing in early effective cardiac compression for such victims enhances the possibility of survival and neurologically favorable outcomes (Holmberg et al., 2000; Koster et al., 2010). Cardiac compression is a relatively complexive basic life support (BLS) task that includes not just an appropriate velocity rate or speed and circulatory-ventilation ratio but also correct hand positioning on the sternum, sufficient compression force to achieve an adequate depth of compression, proper duty cycle, chest decompression, and an adequate surface underneath the victim (Fenici et al., 2005).

Unfortunately, interpretation of data from animal studies is difficult because of the unique anatomy of the chest wall in humans, but it is generally accepted that a standard cardiopulmonary resuscitation (CPR) compression of approximately 1 1/2-2 in (4-5 $\mathrm{cm}$ ) is adequate for the normal-sized adult (Fenici et al., 2005). Cardiac compressions consist of forceful and fast oscillations of the lower half of the sternum (Kouwenhoven et al., 1960). Also, the technique of delivering cardiac compressions is highly standardized and based on international consensus that is updated in 5-year intervals (Berg et al., 2010; Koster et al., 2010; Sayre et al., 2010).

Like this, more efforts to increase the survival ratio on the cardiac arrested has been done, but it may be difficult to understand sufficiently on characteristics of cardiac compression force, and practice and familiarize clearly on the guide manual even though being completed of CPR. Particularly cardiac compression of every 30 times on the cardiac arrested should keep up with high qualitative level and consistency during systole and diastole phase. But it is not clear that cardiac compression force relative to phases should upkeep any degree of level and ratio. Therefore it requires efforts on updated guide manual to understand easily and provide to participants applied on CPR training course (student, ordinary person, employee of exercise rehabilitation, and clinical treatment).

The aim of this study was to verify whether normalization (100\%) of maximal cardiac compression force can evaluate qualitative level and ratio (\%) and maintain consistency during systole
${ }^{*}$ Corresponding author: Che-Cheong Ryew (iD https://orcid.org/0000-0001-9473-3990 Department of Kinesiology, College of Natural Science, Jeju National University, 102 Jejudaehak-ro, Jeju 63243, Korea

E-mail: ryew@jejunu.ac.kr

Received: January 3, 2019 / Accepted: February 6, 2019
This is an Open Access article distributed under the terms of the Creative Commons Attribution Non-Commercial License (http://creativecommons.org/licenses/by-nc/4.0/) which permits unrestricted non-commercial use, distribution, and reproduction in any medium, provided the original work is properly cited. 
and diastole phase. The 1st assumption was set on that diastole force normalized will be approximated nearly to $0 \%$. The 2 nd assumption was set on that maximal compression force relative to compression depth will be occurred. The assumptions was based on the fact that participants was consisted of BSL and career instructors

\section{MATERIALS AND METHODS}

\section{Subject}

Nineteen subjects (mean age, 27.35 \pm 5.91 years; mean heights, $1.76 \pm 0.06 \mathrm{~m}$; mean weights, $74.22 \pm 18.23 \mathrm{~kg}$ ) with BLS and instructor career were participated in this study.

\section{Experimental procedure}

Cardiac compression was executed every 30 times $\times 5$ set on the condition positioned the educational Manikin (Little Anne QCPR, Laerdal, Norway) on ground reaction force (GRF) plate (AMTI-OR-7, Advanced Mechanical Technology Inc., Watertown, MA, USA) and, data sampling ratio was set at 1,000 Hz.

All procedure except for cardiac compression during CPR was omitted, and required 100-120 times per minutes, and compression depth of $5 \mathrm{~cm}$ (adult) according to revised manual and GRF data on only 1 set (30 times) of which, was monitored and stored to personal computer using Kwon GRF 2.0 (Visol, Gwangmyeong, Korea). Then setting on 3-dimension coordinate was defined chest-head direction as anterior-posterior axis, orthogonal direction against chest-head direction as medial-lateral axis, and as or-

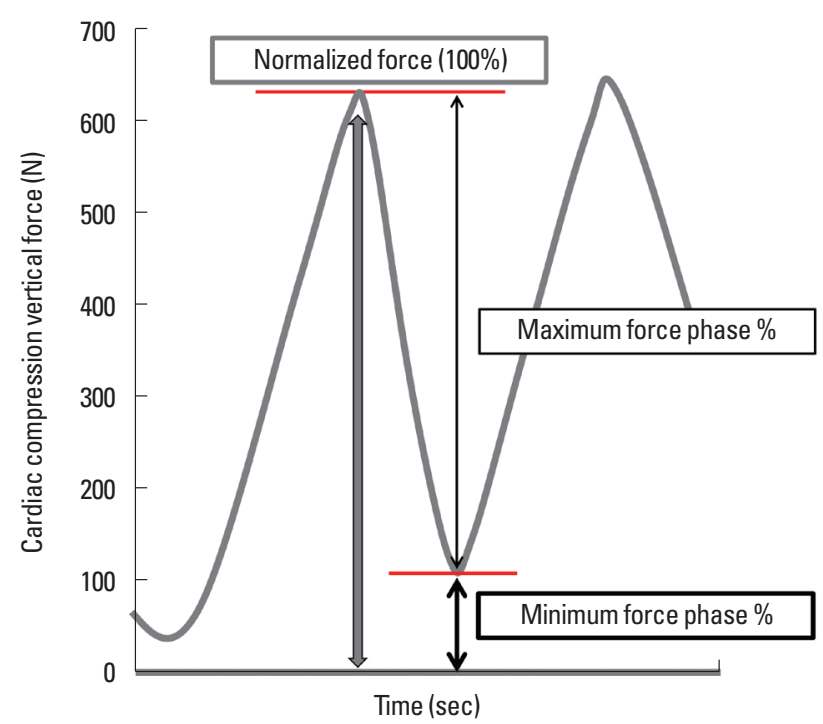

Fig. 1. Cardiac compression vertical force with normalize (100\%).

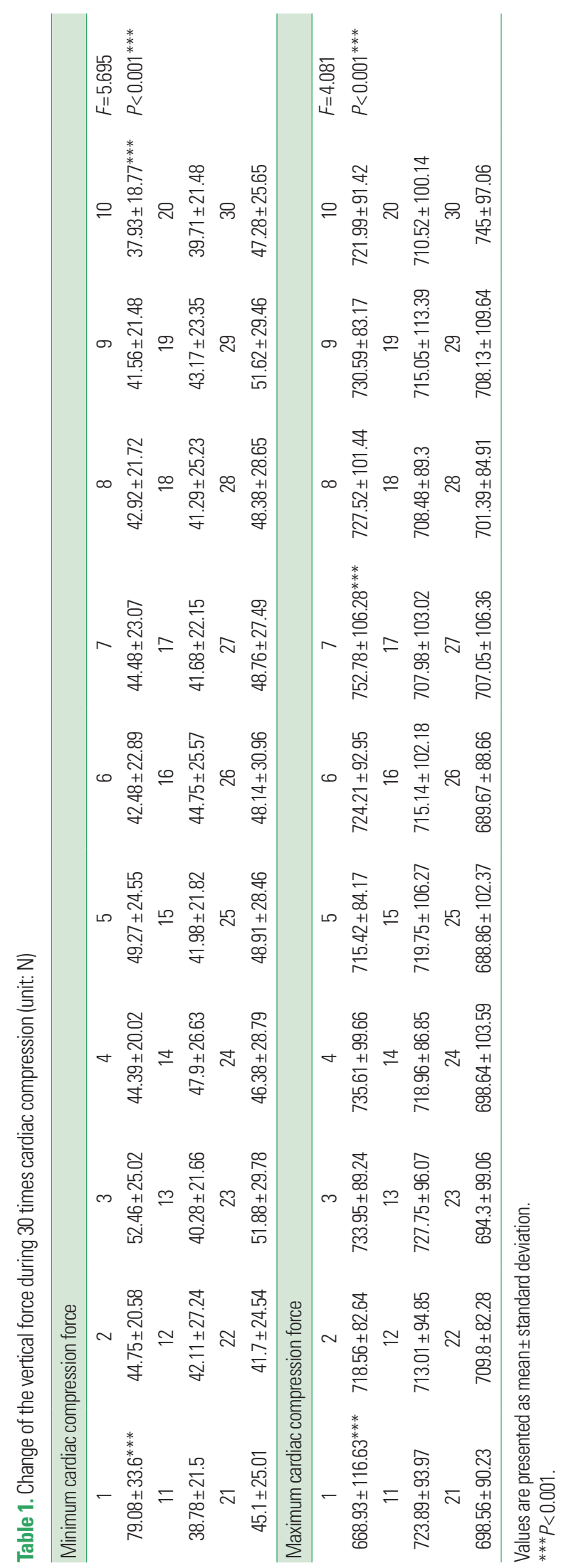


thogonal axis against anterior-posterior-lateral axis respectively.

\section{Definition of analysis phase}

Analyzed data was normalized (100\%) on only maximal vertical force of cardiac compression force, calculated each ratio be- tween diastole and systole phase at the same period, and verified the sum ratio (100\%) of 2 phases (Fig. 1).

\section{Analysis and process of data}

The average and the standard deviation of the calculated vari-

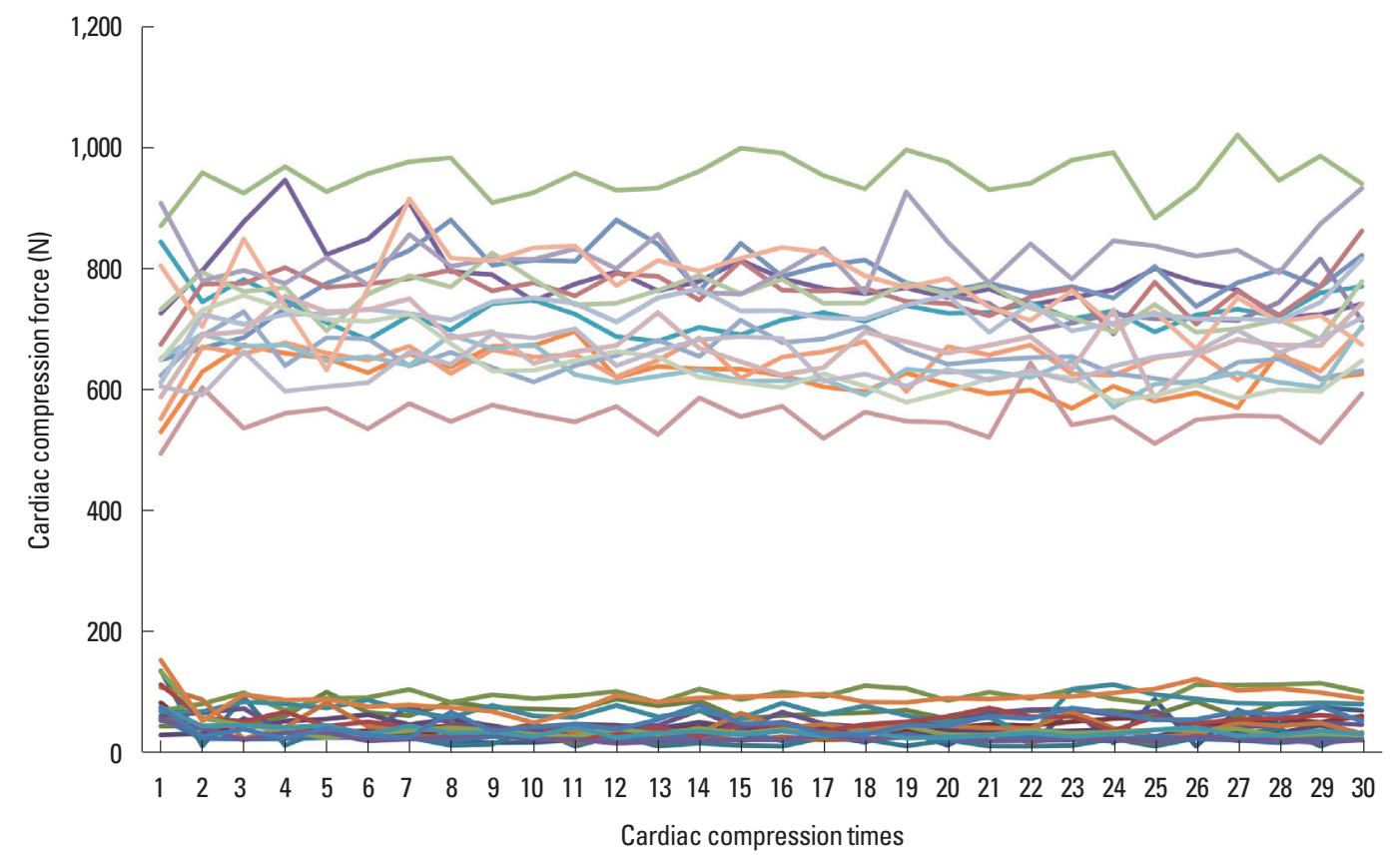

Fig. 2. Pattern of the vertical force during 30 times cardiac compression.

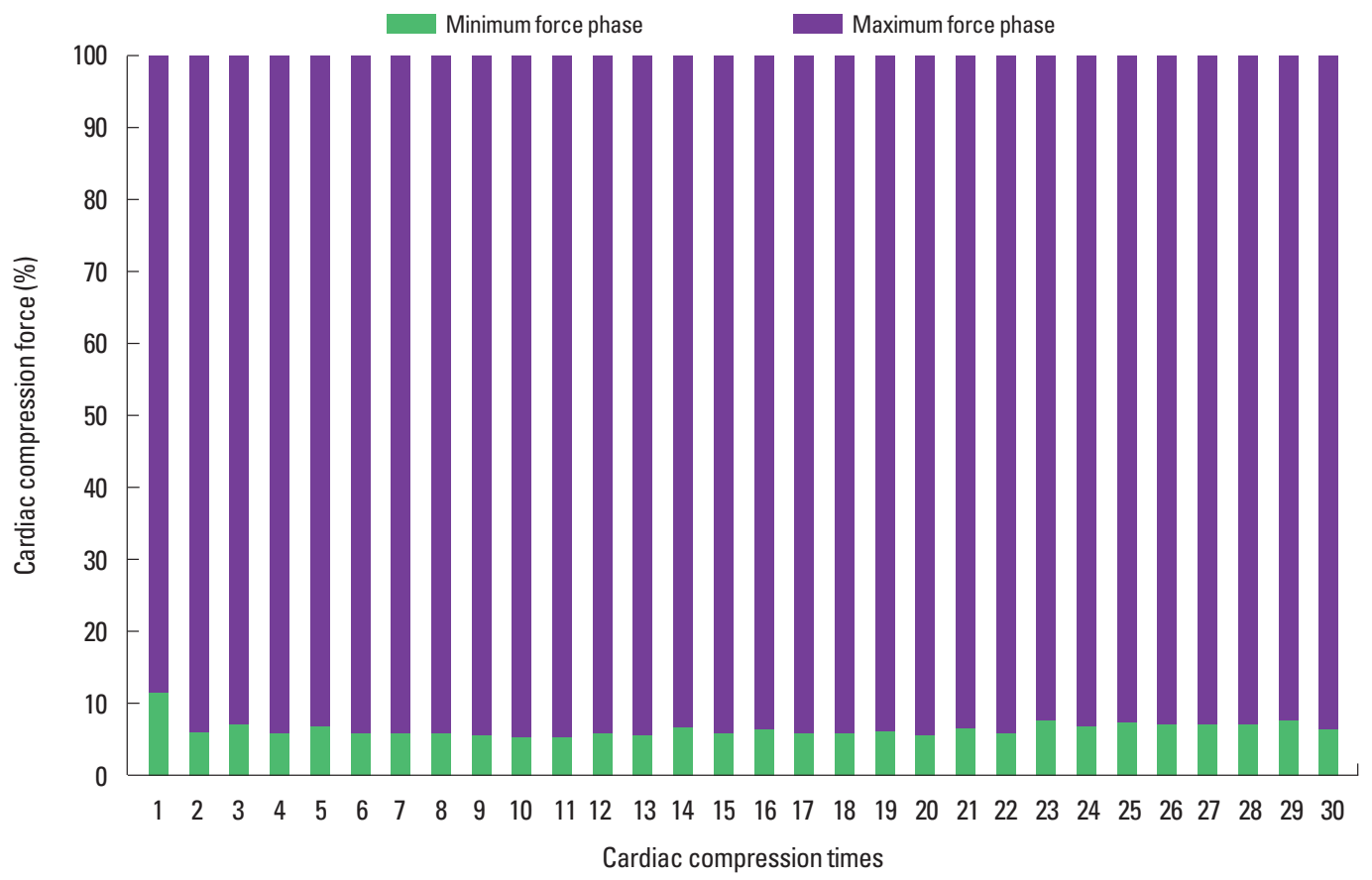

Fig. 3. Ratio between minimum and maximum force phase. 


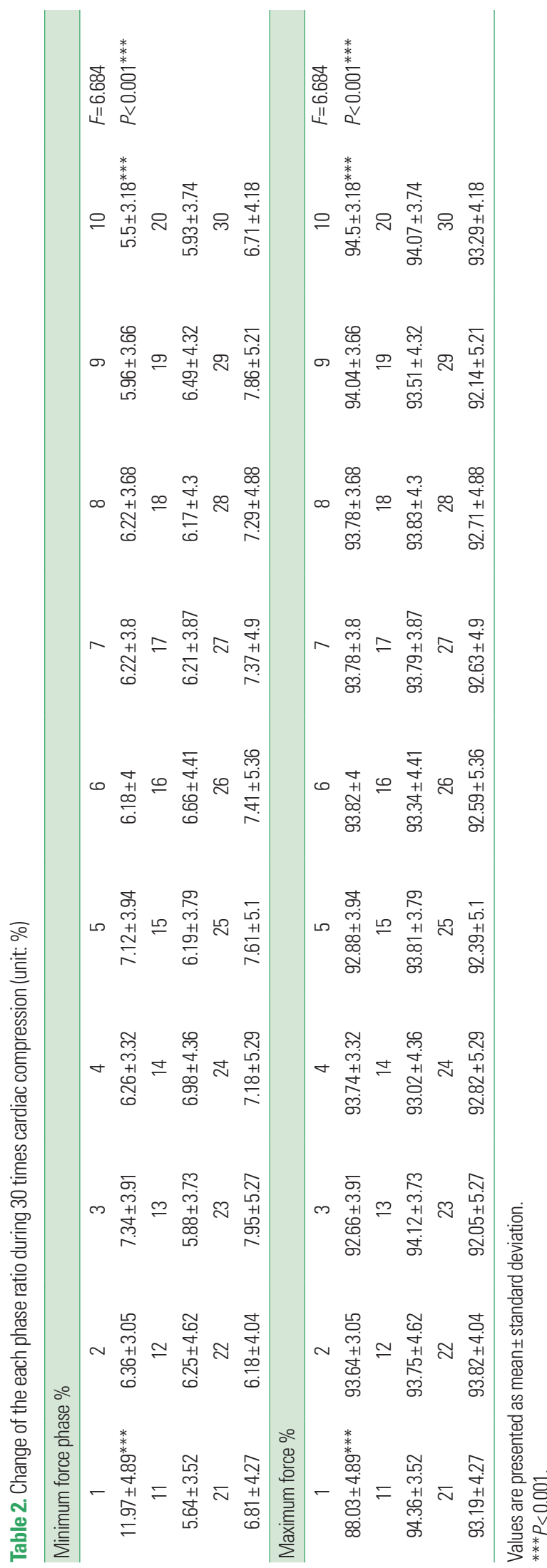

ables were obtained using IBM SPSS Statistics ver. 21.0 (IBM Co., Armonk, NY, USA), and repeated measure one-way analysis of variance for comparisons among each cardiac force $(P<0.05)$.

\section{RESULTS}

Maximal-minimal force against vertical direction which was occurred during 30 times cardiac compression was as Table 1. Fig. 2 meant pattern of vertical force on data of 19 participants. Maximalminimal compression force during 30 times compression showed different pattern, which was significant. Analyzed result by each phases (\%) did not be maintained constant ratio of systole and diastole, which was significant (Table 2, Fig. 3).

\section{DISCUSSION}

Cardiac arrest may result in high mortality by occurring or reoccurring on cardiac patient and normal person, but improve quality of life with exercise rehabilitation program (Gassner et al., 2003). Above all, at occurring of cardiac arrest, proactive trial of CPR is very important, therefore proficient performer must more execute and understand accurately than that of CPR guideline manual on the mechanism of chest compression force particularly in case of a profession because cardiac arrest situation may be generated frequently in sport activity and exercise rehabilitation (Hyun et al., 2018). This study suggested to all participants to perform at diastole force of $0 \%$ nearly. As result, all participants did not maintain the complete diastole force during 30 times of cardiac compression in despite of being BLS or career instructor, thus 1st assumption was rejected. Specifically it showed low level of constancy with range of minimal $37.93 \mathrm{~N}$ to maximal $79.08 \mathrm{~N}$ (mean, $45.97 \pm 25.56 \mathrm{~N}$ ).

In the meanwhile pervious study suggested that proper depth of cardiac compression may accomplish by force of about $50 \mathrm{~kg}$ (Hasegawa et al., 2014; Tomlinson et al., 2007), but this study showed more increased tendency as range of minimal $668.93 \mathrm{~N}$ to maximal $752.78 \mathrm{~N}$ (mean, $714.38 \pm 96.06 \mathrm{~N}$ ) than previous study. That is, consistency showed rather low between 30 times compression, but sufficient force compression was performed equivalent to proper compression depth, thus the 2nd assumption was accepted.

Like the above, this study analyzed $\mathrm{N}$-value on difference of compression force occurring diastole and systole phase, but inference of compression depth by $\mathrm{N}$-value was difficult. Thus this study analyzed normalized diastole and systole phase at each com- 
pression phase. Diastole phase of which, showed complete diastole as approximate to $0 \%$ nearly, and showed range of minimal $5.5 \%$ to maximal $11.97 \%$ (mean, $6.79 \% \pm 4.31 \%$ ) in diastole phase, and also showed range of minimal $88.03 \%$ to maximal $94.5 \%$ (mean, $93.20 \% \pm 4.31 \%$ ) in systole phase.

Thus, when setting the criterion of mean $714 \mathrm{~N}(100 \%)$, insufficient chest diastole (6.80\%) may reduce blood current to coronary and cerebral artery by pressure increase of thoracic cavity and cardiac output (Yannopoulos et al., 2005; Zuercher et al., 2010). But it was not clear how much a significant difference on compression force during systolic and diastolic phase effects on the cardiac arrested. Also, chest compression force during CPR is generated using gravity and hip flexion torque (Trowbridge et al., 2009). Those applying chest compression develop force by accelerating the upper body downwards using gravity, and use hip extension torque to hold the trunk up at decompression, which resists the inertial force of gravity (Trowbridge et al., 2009).

CPR is accompanied with complex movement of body according to guide manual. Therefore, it is necessary to build up system which can adjust duration to extend an activity of CPR instructor and can evaluation and diagnosis for level of understand on characteristics of cardiac compression.

\section{CONFLICT OF INTEREST}

No potential conflict of interest relevant to this article was reported.

\section{REFERENCES}

Berg RA, Hemphill R, Abella BS, Aufderheide TP, Cave DM, Hazinski MF, Lerner EB, Rea TD, Sayre MR, Swor RA. Part 5: adult basic life support: 2010 American Heart Association Guidelines for Cardiopulmonary Resuscitation and Emergency Cardiovascular Care. Circulation 2010; 122(18 Suppl 3):S685-705.

Fenici P, Idris AH, Lurie KG, Ursella S, Gabrielli A. What is the optimal chest compression-ventilation ratio? Curr Opin Crit Care 2005;11:204211.

Gassner LA, Dunn S, Piller N. Aerobic exercise and the post myocardial infarction patient: a review of the literature. Heart Lung 2003;32:258265.
Hasegawa T, Daikoku R, Saito S, Saito Y. Relationship between weight of rescuer and quality of chest compression during cardiopulmonary resuscitation. J Physiol Anthropol 2014;33:16.

Holmberg M, Holmberg S, Herlitz J. Effect of bystander cardiopulmonary resuscitation in out-of-hospital cardiac arrest patients in Sweden. Resuscitation 2000;47:59-70.

Hyun SH, Han JH, Ryew CC. Effect of knee positions on cardiac compression variables in cardiopulmonary resuscitation of rescuer; Manikin study. J Exerc Rehabil 2018;14:530-535.

Koster RW, Baubin MA, Bossaert LL, Caballero A, Cassan P, Castrén M, Granja C, Handley AJ, Monsieurs KG, Perkins GD, Raffay V, Sandroni C. European Resuscitation Council Guidelines for Resuscitation 2010 Section 2. Adult basic life support and use of automated external defibrillators. Resuscitation 2010;81:1277-1292.

Kouwenhoven WB, Jude JR, Knickerbocker GG. Closed-chest cardiac massage. JAMA 1960;9:1064-1067.

Rajab TK, Pozner CN, Conrad C, Cohn LH, Schmitto JD. Technique for chest compressions in adult CPR. World J Emerg Surg 2011;6:41.

Sayre MR, Koster RW, Botha M, Cave DM, Cudnik MT, Handley AJ, Hatanaka T, Hazinski MF, Jacobs I, Monsieurs K, Morley PT, Nolan JP, Travers AH; Adult Basic Life Support Chapter Collaborators. Part 5: Adult basic life support: 2010 International Consensus on Cardiopulmonary Resuscitation and Emergency Cardiovascular Care Science With Treatment Recommendations. Circulation 2010;122(16 Suppl 2): S298-324.

Tomlinson AE, Nysaether J, Kramer-Johansen J, Steen PA, Dorph E. Compression force-depth relationship during out-of-hospital cardiopulmonary resuscitation. Resuscitation 2007;72:364-370.

Trowbridge C, Parekh JN, Ricard MD, Potts J, Patrickson WC, Cason CL. A randomized cross-over study of the quality of cardiopulmonary resuscitation among females performing 30:2 and hands-only cardiopulmonary resuscitation. BMC Nurs 2009;8:6.

Yannopoulos D, McKnite S, Aufderheide TP, Sigurdsson G, Pirrallo RG, Benditt D, Lurie KG. Effects of incomplete chest wall decompression during cardiopulmonary resuscitation on coronary and cerebral perfusion pressures in a porcine model of cardiac arrest. Resuscitation 2005;64:363-372.

Zuercher M, Hilwig RW, Ranger-Moore J, Nysaether J, Nadkarni VM, Berg MD, Kern KB, Sutton R, Berg RA. Leaning during chest compressions impairs cardiac output and left ventricular myocardial blood flow in piglet cardiac arrest. Crit Care Med 2010;38:1141-1146. 